\title{
Significance of Chronic Non-Communicable Diseases and their Threat to the Health of the Population
}

\author{
Damir Pelicic ${ }^{1,2 *}$, Mitar Saveljic ${ }^{1,2}$ and Sonja Nejkov ${ }^{1}$ \\ ${ }^{1}$ Clinical Center of Montenegro, Montenegro \\ ${ }^{2}$ University of Montenegro, Faculty of Medicine, Montenegro
}

*Corresponding author: Damir Pelicic, Center for Science, Clinical Center of Montenegro, Montenegro; University of Montenegro, Faculty of Medicine, Montenegro

\section{ARTICLE INFO

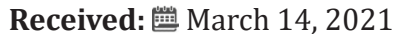

Published: 慧 March 29, 2021

Citation: Damir Pelicic, Mitar Saveljic, Sonja Nejkov. Significance of Chronic NonCommunicable Diseases and their Threat to the Health of the Population. Biomed J Sci \& Tech Res 34(5)-2021. BJSTR. MS.ID.005612.

Keywords: Chronic Noncommunicable Diseases; Epidemic; Morbidity; Mortality

\begin{abstract}
Chronic non-communicable diseases (NCDs) are the leading cause of death in almost all countries of the world and endanger the life and health of people as well as society as a whole. They are the cause of 60 percent of global mortality and 47 percent of total morbidity. The most common are diseases of the heart and blood vessels, malignant diseases, diabetes, chronic respiratory diseases and others. NCD diseases impair human health, affect the significant burden on the health system, reduce productivity and thus significantly affect the quality of life. In terms of the burden of non-communicable diseases in Montenegro, it is similar to that seen in the rest of Europe and most countries around the world.
\end{abstract}

Abbreviations: NCDs: Non-Communicable Diseases; UN: United Nations; CVD: Cardiovascular Disease; WHO: World Health Organization

\section{Short Communication}

"In Montenegro, as in the world, more than any other health problem are chronic non-communicable diseases (NCDs). NCDs aim to form an alliance of a multidisciplinary team of professionals from various fields of biomedicine, health and economics" [1]. The United Nations (UN) clearly informs us that the prevention and control of NCDs cannot be achieved without the use of a "whole society approach", i.e., society as a whole, to make positive behavioral changes to reduce the risks of NCDs, as well as other preventable diseases [1]. Cardiovascular diseases, cancers, chronic respiratory diseases and diabetes are among the leading causes of death and disability in the region, and an increasing number of children and adults live with overweight or obesity [2]. In the developed countries of the world, NCD is the leading public health problem to which the aging population and modern lifestyle contribute to urbanization, industrialization and lifestyle habits harmful to health (smoking, sedentary lifestyle, improper diet, etc.) [3]. The burden on NCDs has been increasing, especially in low / middle income countries. Globally, an estimated 40.5 million in
2016 due to NCDs. Eighty percent of their deaths were caused by diseases including cancer, cardiovascular disease (CVD), chronic respiratory disease and diabetes.

Nearly $80 \%$ of deaths from NCDs occur in people living in subSaharan Africa who face the highest risk of death [4]. Although preventable, NCDs are the leading global causes of morbidity and mortality, absenteeism, disability and premature death. According to a report by the World Health Organization (WHO), more than 36 million people die from NCDs annually, which is about $63 \%$ of the 57 million global deaths. About 16 million people die prematurely, before the age of 70 , during the most productive period of life $[5,6]$. The presence of numerous risk factors that over time lead to the manifestation of the disease, and the importance of chronic noncommunicable diseases is recognized today on a global scale as a threat to human health and development in most countries [7]. Our health care system is relatively small, which is affected by a population of 640,000 inhabitants, according to which Montenegro is one of the small countries, in which according to 2007 data, the 
birth rate was 12.44 per 1,000 inhabitants, mortality rate 9.51 per 1,000 population, which conditioned a positive rate of natural increase of 2.93 per 1,000 inhabitants.

NCDs are the leading causes of illness, disability and premature death of the population before the age of 65 . This system, although small, is also affected by the socio-economic situation, low level of GDP and high unemployment rate, as a serious limiting factor for sustainable financing of health care [8]. "The situation in Montenegro in terms of the burden of non-communicable diseases is very similar to that seen in the rest of Europe and most countries around the world" [9]. The consequences of the socalled epidemiological transition can be seen here. According to available data on deaths in Montenegro from 2010 to 2015, chronic non-communicable diseases are the cause of about $3 / 4$ of the total number of deaths. Of the total number of deaths, almost half of the diseases were caused by heart and blood vessel diseases and almost a quarter by malignant diseases. We still cannot speak reliably about the data on the incidence of non-communicable diseases in Montenegro, because only since 2013, registers for the following non-communicable diseases have been established: malignancies, diabetes, acute coronary syndrome and cerebrovascular diseases [9]. Four additional implementation objectives are directly related to the prevention and control of NCDs: Strengthen the implementation of the WHO Framework Convention on Tobacco Control in all countries, as appropriate.

Support the research and development of vaccines and medicines for communicable and non-communicable diseases that primarily affect developing countries, provide access to affordable essential medicines and vaccines. Health financing, employment, development, training and retention of a health workforce in developing countries, especially in the least developed countries and small developing countries. "The strategic goals we have stated, which were adopted by the World Health Organization (WHO), should support a lifelong approach to health, which promotes healthy behavior, i.e., healthy lifestyles as well as good health, prevention, early detection, diagnosis, risk management, rehabilitation, treatment and care " [10-12]. The conclusion and the main goal that arises from this statement is to strengthen capacities at the global level, especially in developing countries, in order to reduce the risk of developing chronic non-communicable diseases, i.e., their threat to the health of the population and the socio-economic development of the country.

\section{Conflict of Interest}

The authors declares no conflict of interest.

\section{References}

1. Shiffman J (2017) Four challenges facing global health networks. Int J Health Policy Manag 6(4): 183-189.

2. KO overweight (2020) European Health Information Gateway.

3. WHO (2014) Global Status Report on Noncommunicable Diseases 2014. World Health Organization, pp. 298.

4. Bennett JE, Stevens GA, Mathers CD (2018) NKD countdown to 2030: global trends in non-communicable disease mortality and progress towards the goal of sustainable development 3.4. The Lancet 392(10152): 1072-1088

5. WHO (2013) Global Action Plan for the Prevention and Control of Noncommunicable Diseases 2013-2020. World Health Organization.

6. WHO (2012) A comprehensive global monitoring framework, which includes indicators, and a set of voluntary global targets for the prevention and control of non-communicable diseases. World Health Organization.

7. WHO (2008) 2008-2013 Action plan for the Global Strategy for the Prevention and Control of Noncommunicable Diseases. World Health Organization

8. (2019) Montenegro has advanced on the list of European health systems Ministry of Health of Montenegro.

9. Program for control and prevention of non-communicable diseases in Montenegro.

10. WHO (2018) Child and adolescent mental health. World Health Organization.

11. (2018) Tobacco Atlas.

12. WHO (2018) Childhood Cancer. World Health Organization.
ISSN: 2574-1241

DOI: 10.26717/BJSTR.2021.34.005612

Damir Pelicic. Biomed J Sci \& Tech Res

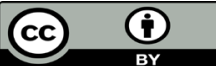

This work is licensed under Creative Commons Attribution 4.0 License

Submission Link: https://biomedres.us/submit-manuscript.php

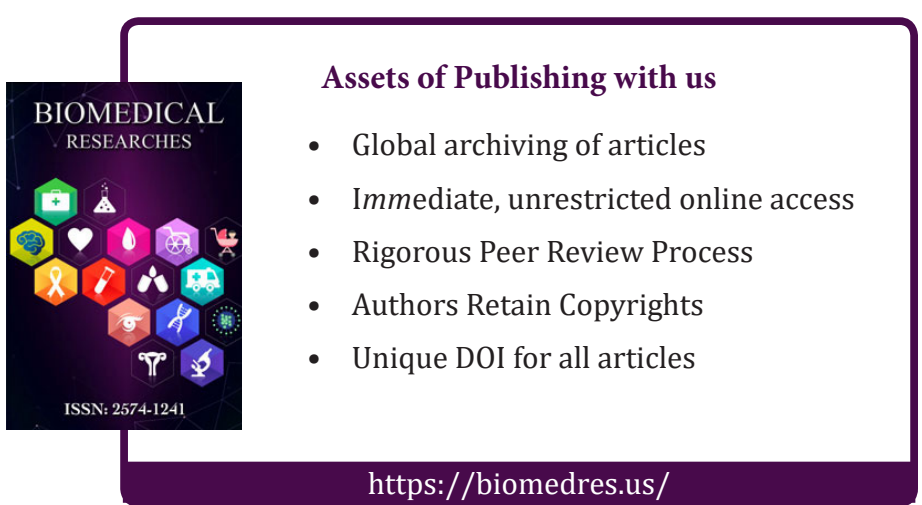

